\section{Percutaneous retrieval of catheter fragments from heart and great vessels: five cases}

The detachment and subsequent central embolisation of an intravenous catheter is a serious event which may give rise to complications such as vascular perforation, thrombosis, or endocarditis. Catheter embolisation now occurs with increasing frequency because of increasing use of central lines. We have recently removed the embolised portions of intravenous catheters from five patients, using a radiological technique and thereby obviating the need for thoracic surgery.

\section{Patients, methods, and results}

Case report-A 13 year old girl in first remission of acute myeloid leukaemia was admitted for further chemotherapy. A Hickman paediatric catheter (Evergreen Medical Products Inc, Washington, USA) was inserted into the right cephalic vein under general anaesthesia. Initially the catheter functioned well but 18 hours after insertion it became blocked. When we tried to remove the catheter its distal $14 \mathrm{~cm}$ segment remained within the patient and a chest radiograph showed that it had embolised to the pulmonary arterial tree. The patient had no symptoms but in order to avert later complications $^{1}$ we decided to remove the detached fragment using a percutaneous radiological technique. A steerable catheter (Medi-tech) was advanced to the pulmonary artery from a right femoral phlebotomy. Using the technique described previously ${ }^{2}$ we ensnared the detached catheter fragment and withdrew it percutaneously. The patient recovered rapidly and chemotherapy for acute leukaemia was resumed.

A total of five procedures of this type have been undertaken at this hospital, and the missing catheters were successfully retrieved in all cases (table). In three patients the embolised catheter fragment had passed through

Details of five cases of embolisation of detached portions of intravenous catheters

\begin{tabular}{|c|c|c|c|c|}
\hline $\begin{array}{l}\text { Case } \\
\text { No }\end{array}$ & $\underset{\text { age }}{\text { Sex and }}$ & $\begin{array}{c}\text { Catheter } \\
\text { type }\end{array}$ & Position & $\begin{array}{c}\text { Type of } \\
\text { anaesthesia }\end{array}$ \\
\hline $\begin{array}{l}1 \\
2\end{array}$ & $\begin{array}{ll}\mathrm{F} & 13 \\
\mathrm{M} & 78\end{array}$ & $\begin{array}{l}\text { Hickman* } \\
\text { Nutricath } †\end{array}$ & $\begin{array}{l}\text { Pulmonary artery } \\
\text { Superior vena cava/ }\end{array}$ & $\begin{array}{l}\text { General } \\
\text { Local }\end{array}$ \\
\hline $\begin{array}{l}3 \\
4 \\
5\end{array}$ & $\begin{array}{ll}F & 48 \\
M & 23 \\
M & 27\end{array}$ & $\begin{array}{l}\text { Nutricath } \\
\text { Nutricath } \\
\text { Bard-I-Cath } \ddagger\end{array}$ & $\begin{array}{l}\text { Pulmonary artery } \\
\text { Right atrium } \\
\text { Right ventricle/ } \\
\text { pulmonary artery }\end{array}$ & $\begin{array}{l}\text { Local } \\
\text { Local } \\
\text { Local }\end{array}$ \\
\hline
\end{tabular}

* Evergreen Medical Products Inc, Washington, USA.

+Vygon, Ecouen, France.
†C R Bard International Ltd, Sunderland, England.

the heart into the pulmonary artery, and retrieval of the missing line was considerably more difficult in these cases than in the remainder, where the line was still in the superior vena cava or right atrium. This was because of the additional catheter manipulation required to enter the pulmonary artery and also because it proved difficult to pull the ensnared fragment back through the pulmonary and tricuspid valves. It is therefore important to try to remove a detached intravenous catheter at the earliest opportunity, when it may still lie in a relatively accessible site proximal to the tricuspid valve.

In all but one of these cases the lines were inserted strictly in accordance with the manufacturer's instructions; in the one exception a Nutricath catheter was partly severed by a cutaneous stitch.

\section{Comment}

Indwelling catheters inserted into the cephalic, subclavian, or jugular veins are routinely used for the administration of parenteral nutrition, cytotoxic agents, and blood products and measurement of central venous pressure. Although catheter embolisation was first reported as a complication of indwelling lines in $1954,{ }^{3}$ it seems to be relatively uncommon: in a study of 355 central venous catheters used for total parenteral nutrition in 200 patients $^{4}$ the major complications noted were related to catheter sepsis (25 catheters $(7 \%)$ and 22 patients) and to catheter insertion ( 14 catheters $(4 \%)$ and 12 patients); no mention was made of catheter embolisation. One series of 29 cases has been reported, ${ }^{5}$ however, and a recent review ${ }^{1}$ emphasised the hazards of retained catheter fragments: the overall potential risk of serious complications in that report was $71 \%$.
One practical problem encountered during these five procedures was difficulty in visualising the detached catheter fragments at fluoroscopy, which would have been easier had the catheters been more radio-opaque

We think that the detachment and embolisation of intravenous catheter fragments is occurring more frequently. The use of noninvasive radiological techniques, as described here, should obviate the need for major thoracic surgery in most cases.

1 Fisher RG, Ferreyro R. Evaluation of current techniques for non-surgical removal of intravascular iatrogenic foreign bodies. American fournal of Roentgenology 1978;130:541-8.

${ }^{2}$ Davies J, Alvares R, Allison DJ. An intracardiac foreign body diagnosed non-invasively and removed non-surgically. $\mathrm{Br} \mathcal{F}$ Radiol 1981 ;54:987-9.

3 Turner DD, Sommers SC. Accidental passage of a polyethylene catheter from cubital vein to right atrium: report of a fatal case. $N$ Engl f Med $1954 ; 251$ :744-5.

4 Ryan JA, Abel RM, Abbott WM, et al. Catheter complications in total parenteral nutrition. $N$ Engl $\mathcal{F}$ Med 1974;290:757-61.

${ }^{5}$ Dotter CT, Rosch J, Bilbao MK. Transluminal extraction of catheter and guide fragments from the heart and great vessels : 29 collected cases. American fournal of Roentgenology 1971;111:467-72.

(Accepted 30 December 1982)

Hammersmith Hospital and Postgraduate Medical School, London W12 OHS

A B MEHTA, MA, MRCP, medical registrar

J M GOLDMAN, DM, FRCP, senior lecturer in medicine

A P HEMINGWAY, MRCP, FRCR, registrar in diagnostic radiology

D J ALLISON, MD, FRCR, consultant in diagnostic radiology

Correspondence and requests for reprints to: Dr D J Allison.

\section{Controlled trial of cimetidine for symptomatic treatment of duodenal ulcers}

Over $10 \%$ of the population may expect to have a duodenal ulcer during their lifetime; most are treated with cimetidine. Most trials so far have concentrated on completely healing ulcers using short term courses of this drug. Probably, however, many patients take the drug only until their symptoms resolve, after one to two weeks. We therefore conducted a prospective trial of cimetidine taken for six weeks versus cimetidine taken only until symptoms were relieved in patients with active duodenal ulceration.

\section{Patients, methods, and results}

Thirty men and women aged over 18 with endoscopically proved active chronic duodenal ulcers and no gastric ulceration were included in the study. Patients who had had previous gastric surgery or taken cimetidine within the previous six weeks were excluded. Patients were randomly allocated to receive cimetidine $200 \mathrm{mg}$ thrice daily and $400 \mathrm{mg}$ at night either for six weeks or for a minimum of one week and thereafter only until their symptoms had completely resolved. Antacid tablets (Gelusil, William Warners) were supplied to be taken as dictated by symptoms. All patients completed diary cards giving details of ulcer pain and the number of both cimetidine and antacid tablets taken. They attended the outpatient clinic every fortnight while taking cimetidine and then every four weeks until either three month after treatment was started or their symptoms recurred, whichever came first. At that stage endoscopy was repeated.

Sixteen patients took cimetidine for six weeks and 14 until their symptoms were relieved. There were no significant differences between the groups in sex distribution, age, alcohol consumption, or smoking. The average time for which the second group took cimetidine was 14.8 days (SD 10.3). The table shows the number of active and healed ulcers in each group at three months or when symptoms recurred if that was sooner, and the number of active but asymptomatic ulcers in each group. The numbers of active ulcers at the end of the trial did not differ significantly between the two groups. The average time between stopping cimetidine and repeat endoscopy in patients who had recurrent symptoms with active ulceration was 33 days in 